\title{
Engineering 3D electron and ion transport channels by constructing sandwiched holey quaternary metal oxide nanosheets for high-performance flexible energy storage
}

\author{
Pingping Yao ${ }^{1}$, Jiali Yu ${ }^{1 *}$, Jie Zhou ${ }^{1}$, Shuo Zhang ${ }^{1}$, Meng Zhang ${ }^{1}$, Huichao Liu ${ }^{1}$, Bo Yang ${ }^{1}$, \\ Tao Zhang ${ }^{2,3}$, Caizhen $\mathrm{Zhu}^{{ }^{*}}$ and Jian $\mathrm{Xu}^{1}$
}

\begin{abstract}
Due to the enhanced electrochemical activities, mixed metal oxides offer new and fascinating opportunities for high-performance supercapacitor electrodes. However, sluggish ionic and electronic kinetics within the electrode fundamentally limit further improvement of their electrochemical performance. To compensate for the deficiency, a flexible electrode (CNTF/Ni-Co-Mn-Mo NS/CNTN) composed of vertically-aligned areolate quaternary metal oxide nanosheets sandwiched between carbon nanotubes (CNTs) is constructed in this study, which demonstrates a unique hierarchical porous structure that can provide three-dimensional transport channels for both ions and electrons. The vertically aligned areolate quaternary metal oxide nanosheets enable increased exposed surface area and paths for ion transport, diffusion and redox reactions, resulting in an evident enhancement in electrochemical activities. Besides, the CNT networks provide improved conductivity, which can accelerate the electron transport. As a result, the flexible supercapacitor based on the CNTF/Ni-Co-Mn-Mo NS/CNTN electrode demonstrates a specific areal capacitance of $3738 \mathrm{mF} \mathrm{cm}$, corresponding to a high energy density of $1.17 \mathrm{~mW} \mathrm{~h} \mathrm{~cm}{ }^{-2}$, which outperforms most of the flexible devices reported recently. Additionally, excellent flexibility of up to $180^{\circ}$ bend and superior performance stability of $87.87 \%$ capacitance retention after 10,000 charge-discharge cycles can be obtained. This unique design opens up a new way in the development of flexible energy storage devices with high performance.
\end{abstract}

Keywords: supercapacitor, quaternary metal oxide, carbon nanotube, pseudocapacitive materials

\section{INTRODUCTION}

The rapid depletion of fossil fuel and ever worsening environmental issues urgently call for renewable alternative energy sources such as solar, wind, tide and wave energy [1,2]. To conquer the intrinsic disadvantages of the intermittent power generation from these clean energy sources, it is of crucial importance to develop applicable and reliable energy storage devices [3]. Among numerous electrochemical energy storage and conversion devices, supercapacitor is the most promising approach that has been intensively studied, due to its combined advantages of high power density, long operational life, fast charge-discharge rate and excellent safety [4-6]. However, the energy density of supercapacitors is relatively low compared with batteries, limiting wide applications of this cutting-edge technology. To address this problem, numerous efforts have been devoted to highperformance pseudocapacitive electrode materials [7-9]. The objective is to design and fabricate electrode materials which can achieve high energy density without sacrificing the power density and long cycling life [10-12].

Accordingly, the family of mixed metal oxides that composed of two different cations have played a key role in the successful implementation of high-performance supercapacitor electrodes due to several advantages over the simple metal oxide, including short-distance interactions between charge carriers and ions, and high electrochemical activities derived from the complex redox

\footnotetext{
${ }^{1}$ Institute of Low-dimensional Materials Genome Initiative, College of Chemistry and Environmental Engineering, Shenzhen University, Shenzhen 518060, China

${ }^{2}$ Research Institute of Tsinghua University in Shenzhen, Shenzhen 518057, China

${ }^{3}$ Institute of Nuclear and New Energy Technology, Tsinghua University, Beijing 100084, China

* Corresponding authors (emails: jlyyhx@163.com (Yu J); czzhu@szu.edu.cn ( Zhu C))
} 
chemistry $[13,14]$. Moreover, recently, there have been several studies on the successful preparation and application of ternary metal oxide/hydroxide/sulfide nanowires as the active materials for supercapacitors [15-21]. It has been demonstrated that the incorporation of multications into metal compounds can offer an evident enhancement of electrochemical activities and electron transportation $[20,22]$. However, it is still far from reality because of their inferior conductivities, sluggish ionic kinetics and structural instability which result in low power performance and obvious capacity fading during cycling. Besides, it is challenging and imperative to further improve the specific capacitances that are in direct proportion to energy densities $\left(E=1 / 2 C V^{2}\right)$ [23].

It has been well known that the energy storage performance of a supercapacitor electrode is mainly determined by the electrochemical activity and the kinetics of active materials. Therefore, to achieve high energy densities without sacrificing power densities, two main issues should be addressed in the design of the electrode materials, one is enhancing the mass transfer rate of ions and electrons in electrodes and at the electrode/electrolyte interface; the other is ensuring sufficient electroactive sites exposed on the surface for redox reactions [24].

Based on the above considerations, herein, a new type of areolate quaternary metal oxide nanosheets composed of $\mathrm{Ni}, \mathrm{Co}, \mathrm{Mn}$ and Mo cations was successfully grown on carbon nanotube film (CNTF) and formed an open macroporous architecture. The three-dimensional (3D) hierarchical porous channels formed by the areolate quaternary metal oxide nanosheets favor the efficient electrolyte penetration and transport which can improve the contact between the active surface and electrolyte. CNT network (CNTN) was further wrapped over the areolate nanosheets through an effective electrophoretic deposition (EPD) process to form a $3 \mathrm{D}$ conductive framework for accelerating electron transfer within the electrode. In this unique hierarchical electrode architecture, 3D highways of both electrolyte ions and electrons were simultaneously built, which can facilitate effective energy storage, realizing maximum utilization of electroactive materials at high current densities. As a result, an ultrahigh specific areal capacitance of $15.39 \mathrm{~F} \mathrm{~cm}^{-2}$ was obtained at the current density of $1 \mathrm{~mA} \mathrm{~cm}{ }^{-2}$. By using this hierarchical electrode, a flexible asymmetric supercapacitor was fabricated, which demonstrated a wide voltage window of $1.5 \mathrm{~V}$, excellent energy density of $1.17 \mathrm{mWh} \mathrm{cm}^{-2}$, power density of $13.40 \mathrm{~mW} \mathrm{~cm}^{-2}$, along with outstanding cycling stability and flexibility.

\section{EXPERIMENTAL SECTION}

\section{Preparation of CNTF/Ni-Co-Mn-Mo oxide nanosheets} (CNTF/Ni-Co-Mn-Mo NS), CNTF/Ni-Co-Mn oxide (CNTF/ Ni-Co-Mn) and CNTF/Ni-Co oxide (CNTF/Ni-Co)

The CNTF was purchased from Nanjing Xianfeng Nanomaterial Technology Co. LTD, China (XFNANO). CNTF was firstly immersed in a mixed acid solution for $24 \mathrm{~h}$ at ambient temperature to remove the adsorbed impurities and improve the wettability. The mixed acid solution was composed of concentrated sulfuric acid and concentrated nitric acid with a volume ratio of 3:1. Then CNTF was taken out and thoroughly rinsed with deionized water followed by drying in an oven for $12 \mathrm{~h}$ at $60^{\circ} \mathrm{C}$.

The solution used for CNTF/Ni-Co-Mn-Mo NS preparation consisted of $0.1007 \mathrm{~g}$ of $\mathrm{Mn}\left(\mathrm{NO}_{3}\right)_{2}, 0.3271 \mathrm{~g}$ of $\mathrm{Ni}\left(\mathrm{NO}_{3}\right)_{2} \cdot 6 \mathrm{H}_{2} \mathrm{O}, 0.6535 \mathrm{~g}$ of $\mathrm{Co}\left(\mathrm{NO}_{3}\right)_{2} \cdot 6 \mathrm{H}_{2} \mathrm{O}, 0.1986 \mathrm{~g}$ of $\left(\mathrm{NH}_{4}\right)_{2} \mathrm{MoO}_{4}, 0.2726 \mathrm{~g}$ of $\mathrm{CO}\left(\mathrm{NH}_{2}\right)_{2}, 0.0556 \mathrm{~g}$ of $\mathrm{NH}_{4} \mathrm{~F}$ and $30 \mathrm{~mL}$ of deionized water. The acid-treated CNTF was mixed with the solution and transfered into a $50-\mathrm{mL}$ Teflon-lined stainless-steel autoclave. The autoclave was then sealed and kept at $130^{\circ} \mathrm{C}$ for $5 \mathrm{~h}$. After cooling down to room temperature, CNTF/Ni-Co-Mn-Mo NS was taken out and washed with deionized water for several times and dried at $60^{\circ} \mathrm{C}$ for $12 \mathrm{~h}$. Finally, the CNTF/NiCo-Mn-Mo NS was annealed at $350^{\circ} \mathrm{C}$ for $4 \mathrm{~h}$ to obtain the CNTF/Ni-Co-Mn-Mo NS electrode. Same procedures were conducted to prepare $\mathrm{CNTF} / \mathrm{Ni}$-Co and $\mathrm{CNTF} / \mathrm{Ni}$ Co-Mn, except that the transition metal cations in the solutions used for hydrothermal process were changed: $\mathrm{Ni}^{2+} / \mathrm{Co}^{2+}$ for $\mathrm{CNTF} / \mathrm{Ni}-\mathrm{Co} ; \mathrm{Ni}^{2+} / \mathrm{Co}^{2+} / \mathrm{Mn}^{2+}$ for $\mathrm{CNTF} /$ $\mathrm{Ni}-\mathrm{Co}-\mathrm{Mn}$.

\section{Preparation of CNTF/Ni-Co-Mn-Mo oxide nanosheets/ CNTN (CNTF/Ni-Co-Mn-Mo NS/CNTN)}

An electrolyte containing $3 \mathrm{~g}$ of commercially available carboxylic CNTs (3A Chemicals), $15 \mathrm{mg}$ of polyethyleneimine ( $M \mathrm{w} 25,000)$ and $30 \mathrm{~mL}$ of deionized water was firstly prepared by ultrasonication for $30 \mathrm{~min}$. For the EPD process, the CNTF/Ni-Co-Mn-Mo NS and copper foam were used as the cathode and anode respectively and immersed in the electrolyte. Then a constant voltage of $30 \mathrm{~V}$ was applied on the CNTF/Ni-Co-Mn-Mo NS for 15 min to deposit CNTN. The resulting CNTF/Ni-CoMn-Mo NS/CNTN was dried in an oven at $120^{\circ} \mathrm{C}$ for $24 \mathrm{~h}$.

Fabrication of flexible asymmetric supercapacitor The asymmetric supercapacitor was built with $\mathrm{CNTF} / \mathrm{Ni}$ - 
Co-Mn-Mo NS/CNTN as the positive electrode, carbon cloth as the negative electrode and $\mathrm{KOH} /$ poly(vinyl alcohol) (PVA) as the gel electrolyte. In a typical process, CNTF/Ni-Co-Mn-Mo NS/CNTN and carbon cloth were adhered to a non-conductive polyethylene terephthalate flexible substrate and separated by $\mathrm{KOH} / \mathrm{PVA}$ gel to form a sandwiched structure, resulting in a flexible asymmetric supercapacitor.

\section{RESULTS AND DISCUSSION}

The design and preparation of the CNTF/Ni-Co-Mn-Mo NS/CNTN electrode are illustrated in Fig. 1. The whole process involved three simple steps. First, Ni-Co-Mn-Mo oxide were in-situ grown on CNTF through a facile hydrothermal process. The as prepared Ni-Co-Mn-Mo oxides displayed an areolate mesoporous nanosheet morphology and were lap-jointed with each other to form macropores on CNTF over a large area. After annealing, the as grown porous $\mathrm{Ni}-\mathrm{Co}-\mathrm{Mn}-\mathrm{Mo} \mathrm{NS}$ served as a backbone for the following deposition of CNTNs. It should be noted that, in some previously reported studies, dip-coating method was usually applied to coat CNTs on the target nanostructures, while the dip-coating technology led to non-uniform distributions of CNTs and loose contacts between CNTs and the backbone [25]. In this study, a simple but effective EPD process was applied to tightly attach CNTN on Ni-Co-Mn-Mo NS and form a uniform conductive network that fully entangled with the metal oxide backbones. The total loading density of $\mathrm{Ni}$ Co-Mn-Mo oxide/CNTN is about $6 \mathrm{mg} \mathrm{cm}^{-2}$. In this nano-architecture, mesh-like CNTN works as a conductive 3D framework that promotes the electron transfer in the electrode, while the hierarchical-porous quaternary metal oxide nanosheets can provide extra pathways for ions permeation and transport. Both of the above mentioned factors play vital roles in the enhancement of energy storage. Besides, the unique nanostructure can also provide better exposed surface area, and complex valence change for energy storage, leading to excellent energy storage performances.

Fig. 2a, b show the typical scanning electron microscopy (SEM) images of the CNTF/Ni-Co-Mn-Mo NS at different magnifications. CNTF, which is functioned as a flexible substrate and highly conductive current collector, is composed of randomly oriented multi-walled CNTs with diameters of about $10 \mathrm{~nm}$ and lengths of dozens micrometers (Fig. S1). As can be seen, after the hydrothermal process, the nanosheets are uniformly grown on the surface of CNTF over a large area. These nanosheets are loaded vertically and interconnected with each other, forming a highly open and porous structure, indicating that the nanosheet surface is highly accessible for electrolyte permeation and redox reactions when used as the supercapacitor electrode. Of particular note is that the

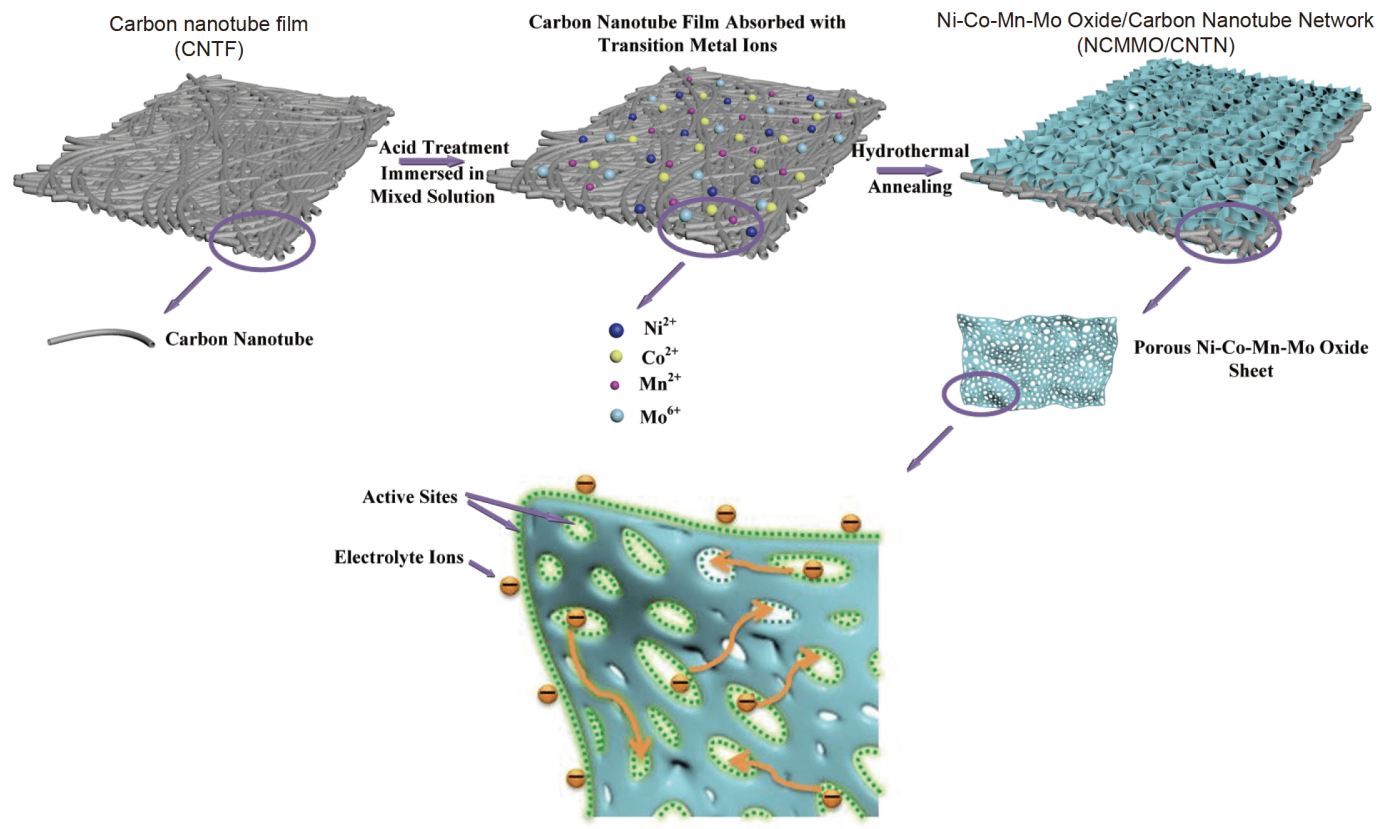

Figure 1 Schematic illustration of the synthesis protocol of the CNTF/Ni-Co-Mn-Mo NS/CNTN flexible electrode. 

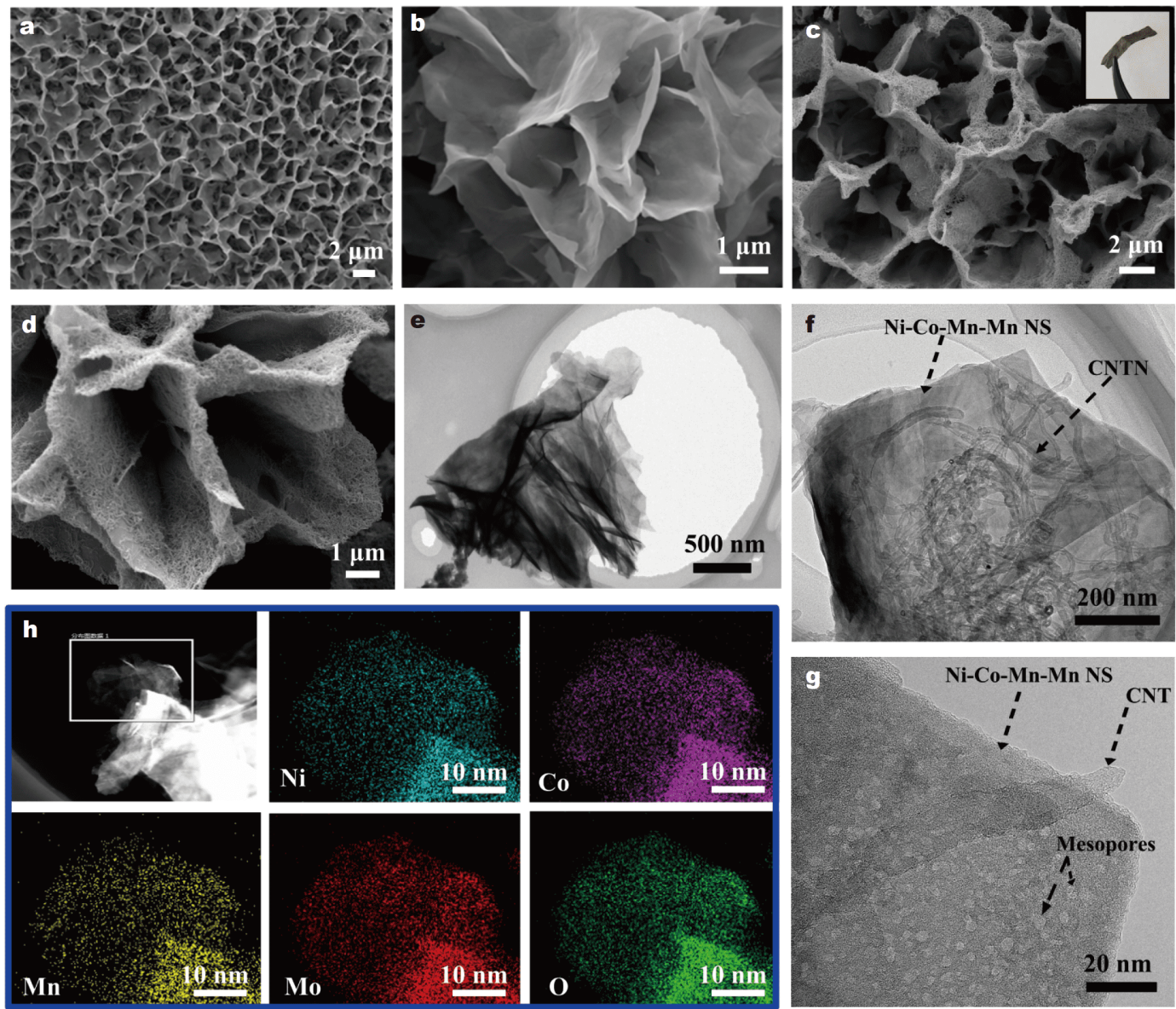

Figure 2 (a, b) SEM images of CNTF/Ni-Co-Mn-Mo NS electrode at low and high magnifications. (c, d) SEM images of CNTF/Ni-Co-Mn-Mo NS/ CNTN electrode at low and high magnifications; the inset shows the optical image of the freestanding CNTF/Ni-Co-Mn-Mo NS/CNTN electrode. (e) TEM image of a Ni-Co-Mn-Mo NS. (f) TEM image and (g) HRTEM image of the Ni-Co-Mn-Mo NS/CNTN composite. (h) EDX mappings of a NiCo-Mn-Mo NS.

thickness of the nanosheet is measured to be less than $30 \mathrm{~nm}$ (Fig. S2). Since it has been known that the electrolyte can only diffuse into the active materials with a depth of $20 \mathrm{~nm}[26,27]$, the thin nature of the as-synthesized nanosheets guarantees that most parts of the active materials can be accessed by electrolyte ions via diffusing from both side of the nanosheets. After CNTN deposition, it can be found that network-like CNTs tightly and uniformly covered the surface of nanosheets (CNTF/Ni-Co-Mn-Mo NS/CNTN; Fig. 2c, d). Herein, the as-decorated CNTN plays a key role in accelerating electron transfer with the whole electrode during the electrochemical reactions, which is especially favorable for the enhancement of supercapacitor performance. Transmission electron microscopy (TEM) images provide further insight into the detailed structure of the nanosheets and CNTN/nanosheet composite. Typical TEM image of the nanosheet (Fig. 2e) reveals its wrinkled silklike texture with no obvious cracks around the folded areas, indicating its excellent flexibility. As for the composite, CNTN is evidenced on the nanosheet surface even after a 10 min ultrasonic process (during the TEM sample preparation; Fig. 2f), which indicates that the EDP method can strongly bond CNTs on the target metal compound, resulting in effective and imperishable conductive paths for electrons. In addition, it is pleasantly surprising to find that, in the high-resolution TEM (HRTEM) image of the pure nanosheet (Fig. S3) and CNTN/nanosheet composite (Fig. 2g), the nanosheet demonstrates a unique areolate structure with numerous uniform mesopores located on it. These pores can provide extra active sites for electrochemical reactions and extra channels for the ion transportation, thus further improving the electroactivity of the electrode. Energy 
dispersive X-ray (EDX) mapping analysis reveals the homogeneous full spatial dispersions and coexistence of $\mathrm{Ni}, \mathrm{Co}, \mathrm{Mn}, \mathrm{Mo}$ and $\mathrm{O}$ across the the $2 \mathrm{D}$ nanosheet (Fig. 2h), unambiguously manifesting that the metal oxide nanosheet is composed of four metal cations.

The Raman spectra of pristine CNTF, CNTN, CNTF/ Ni-Co-Mn-Mo NS and CNTF/Ni-Co-Mn-Mo NS/CNTN are given in Fig. 3a. The red line shows the Raman spectrum of pristine CNTF. An $I_{\mathrm{G}} / I_{\mathrm{D}}$ ratio of 1.93 can be obtained, indicating the high graphitic level in the CNTF, which is beneficial for the electron conductivity of CNTF. The blue line shows the Raman spectrum of the CNTs that used for CNTN deposition, which demonstrates a much lower $I_{\mathrm{G}} / I_{\mathrm{D}}$ ratio (0.91) as compared with the value for CNTF. The difference between the two CNT samples is due to that the CNTs in CNTN were carboxylated to increase their dispersibility in the electrolyte solution for EPD. The carboxylation of CNT can introduce oxygencontaining polar groups and defects into CNTs in CNTN, leading to decreased graphitic level. As for $\mathrm{CNTF} / \mathrm{Ni}-\mathrm{Co}-$ Mn-Mo NS, in addition to the CNTF peaks, the Raman bands located at about 333,537, 848 and $927 \mathrm{~cm}^{-1}$ are associated with the shaking peaks of metal oxide nanostructures [25-29]. After the deposition of CNTN, it can be seen from the spectrum of CNTF/Ni-Co-Mn-Mo NS/ CNTN that all the typical peaks for metal oxide are well preserved, except that the intensity ratio of $I_{\mathrm{G}} / I_{\mathrm{D}}$ is sa- milar with that of CNTN (due to that CNTN is located on top of the composite electode, while CNTF is at the bottom. Thus the Raman spertcum of CNTF/Ni-Co-MnMo NS/CNTN shows the Raman peaks for $\mathrm{CNCN}$ ), further verifying the successful loading of CNTN.

The chemical composition and electronic bonding states of the quaternary metal oxide were further analyzed by X-ray photoelectron spectroscopy (XPS). Survey spectrum of the CNTF/Ni-Co-Mn-Mo NS/CNTN gives the peaks of Ni, Co, Mn, Mo, O and C elements (Fig. S4). The deconvolution of $\mathrm{O}$ 1s spectrum in Fig. $3 \mathrm{~b}$ shows two peaks: one is attributed to the metal-oxygen bonds and the other peak is assigned to $\mathrm{C}=\mathrm{O}, \mathrm{O}-\mathrm{C}=\mathrm{O}$ bonds from CNTs [28]. The high-resolution XPS spectrum of Ni $2 \mathrm{p}$ (Fig. 3c) demonstrates $\mathrm{Ni} 2 \mathrm{p}_{3 / 2}$ and $\mathrm{Ni} 2 \mathrm{p}_{1 / 2}$ peaks along with their two satellite peaks (marked as "sat."). The Ni $2 \mathrm{p}_{3 / 2}$ and $\mathrm{Ni} 2 \mathrm{p}_{1 / 2}$ can be further divided into two spinorbit doublets, indicating the coexistence of $\mathrm{Ni}^{2+} / \mathrm{Ni}^{3+}$ [30]. The deconvoluted spectra of Co $2 \mathrm{p}$ region have Co $2 \mathrm{p}_{3 / 2}$ and Co $2 \mathrm{p}_{1 / 2}$ peaks that split into two spin-orbit lines. These peaks along with the shake-up satellites in Co $2 p$ spectrum evidence the presence of divalent and trivalent Co species (Fig. 3d) [31]. In the Mn 2p spectra, two major peaks centered at 642.2 and $653.9 \mathrm{eV}$ with an energy separation of $11.7 \mathrm{eV}$ are related to quadrivalent $\mathrm{Mn}$. The other two peaks located at 643.9 and $652.3 \mathrm{eV}$ are the characteristic peaks of $\mathrm{Mn}^{2+}$ (Fig. 3e) [32,33]. Deconvo-
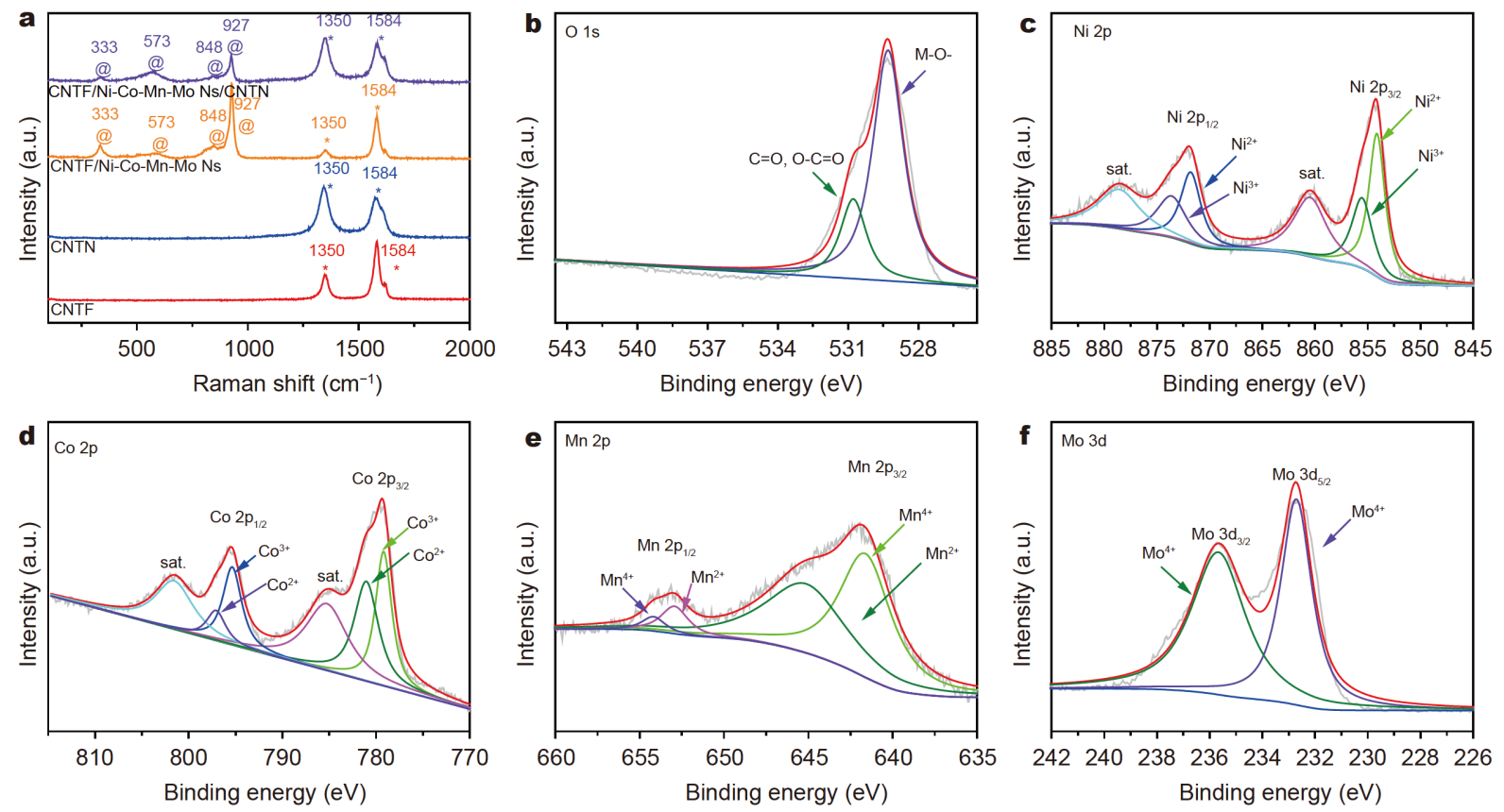

Figure 3 (a) Raman spectra of different samples. High resolution XPS spectra of (b) O 1s, (c) Ni 2p, (d) Co 2p, (e) Mn 2p and (f) Mo 3d for CNTF/ Ni-Co-Mn-Mo NS/CNTN electrode. 
lution of Mo 3d shows two distinguished peaks at 232.5 and $235.7 \mathrm{eV}$, which are corresponding to $M o 3 \mathrm{~d}_{5 / 2}$ and Mo $3 \mathrm{~d}_{3 / 2}$, respectively (Fig. 3f) [16]. The complex chemical composition and oxidation states of Ni-Co-Mn-Mo NS would provide improved electrochemical activities for energy storage.

The electrochemical performances of the electrodes were evaluated in a three-electrode system with $1 \mathrm{~mol} \mathrm{~L}^{-1}$ $\mathrm{KOH}$ aqueous solution as the electrolyte. Fig. 4a shows the comparative cyclic voltammetry (CV) curves of CNTF/Ni-Co, CNTF/Ni-Co-Mn, CNTF/Ni-Co-Mn-Mo NS and CNTF/Ni-Co-Mn-Mo NS/CNTN at a constant scan rate of $2 \mathrm{mV} \mathrm{s}^{-1}$ within a potential window of $0-0.5 \mathrm{~V}$. From Fig. $4 \mathrm{a}$, a pair of redox peaks can be clearly observed in all the CV curves, indicating that the capacitances are mainly derived from the pseudocapacitance associated with reversible Faradic reactions of the transition metal oxide. The highest integrated area of $\mathrm{CV}$ curve belongs to CNTF/Ni-Co-Mn-Mo NS/CNTN electrode, indicating its highest specific capacitance among the four samples. In addition, it is noticeable that the peak current response and peak area of metal oxide-decorated CNTF samples follow the sequence that $\mathrm{CNTF} / \mathrm{Ni}$ $\mathrm{Co}<\mathrm{CNTF} / \mathrm{Ni}-\mathrm{Co}-\mathrm{Mn}<\mathrm{CNTF} / \mathrm{Ni}-\mathrm{Co}-\mathrm{Mn}-\mathrm{Mo}$ NS, indicating that the metal oxide-containing quaternary cations is more electrochemically active than its ternary and binary counterparts. Meanwhile, according to the redox behavior of CNTF/Ni-Co-Mn-Mo NS and CNTF/Ni-CoMn-Mo NS/CNTN, the loading of CNTN brings the current response of CNTF/Ni-Co-Mn-Mo NS/CNTN to a higher level. Besides, by comparing the electrode impedance spectroscopy (EIS) results of CNTF/Ni-Co-Mn-
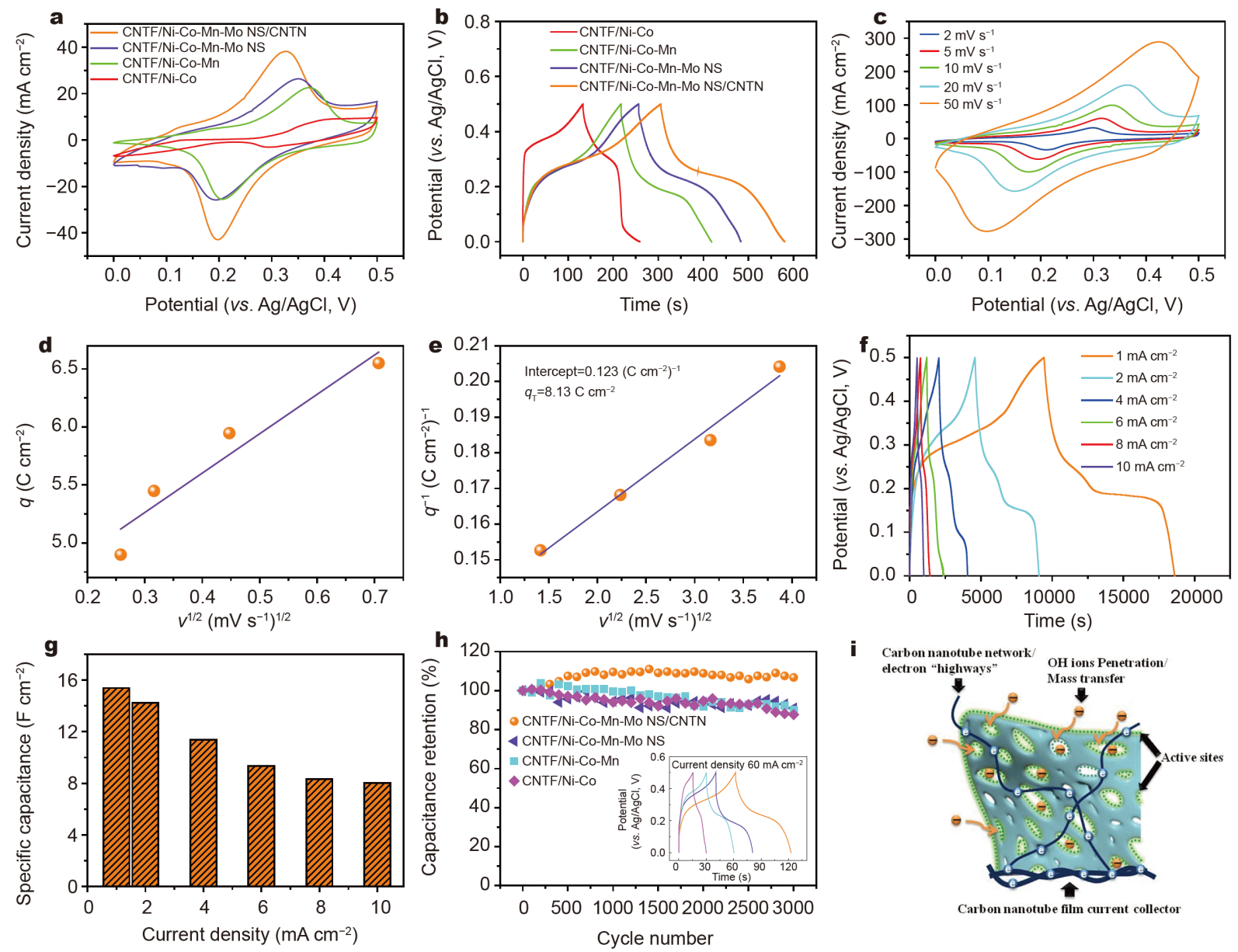

Figure 4 (a) $\mathrm{CV}$ at $2 \mathrm{mV} \mathrm{s}^{-1}$, (b) GCD curves of different samples. (c) CV curves of CNTF/Ni-Co-Mn-Mo NS/CNTN at different scan rates. Calculations of (d) $q_{\mathrm{o}}$ and (e) $q_{\mathrm{T}}$ for CNTF/Ni-Co-Mn-Mo NS/CNTN electrode. (f) GCD curves of CNTF/Ni-Co-Mn-Mo NS/CNTN electrode at different current densities. (g) Specific areal capacitance of CNTF/Ni-Co-Mn-Mo NS/CNTN electrode versus current density. (h) Capacitance retention during $3000 \mathrm{GCD}$ cycles for different samples; the inset shows the $3000^{\text {th }} \mathrm{GCD}$ curves of different samples tested at $60 \mathrm{~mA} \mathrm{~cm}^{-2}$. (i) Schematic representation showing the merits of CNTF/Ni-Co-Mn-Mo NS/CNTN electrode. 
Mo NS and CNTF/Ni-Co-Mn-Mo NS/CNTN electrodes, it can be seen that after CNTN deposition, the equivalent series resistance (ESR) and charge transfer resistance $\left(R_{\mathrm{ct}}\right)$ of the CNTF/Ni-Co-Mn-Mo NS/CNTN electrode has been reduced from 4.85 to $3.56 \Omega$ and 1.96 to $1.11 \Omega$, respectively (Fig. S5). Both of the results demonstrate that the $3 \mathrm{D}$ channels provided by the porous quaternary metal oxide and CNTN are favorable for fast diffusion of electrolyte ion and electron transportations during the electrochemical reactions, thus leading to higher electrochemical activity and energy storage performance. Meanwhile, same conclusion can also be drawn from Fig. 4b, which shows the galvanostatic charge discharge (GCD) curves of different samples at a current density of $14 \mathrm{~mA} \mathrm{~cm}^{-2}$. Obviously, the discharging time of CNTF/ Ni-Co-Mn-Mo NS/CNTN electrode is the longest as compared with its dual, ternary and quaternary oxide counterparts at the same current density, indicating that the CNTF/Ni-Co-Mn-Mo NS/CNTN electrode possesses the highest specific capacitance. Besides, it should be noted that, compared with $\mathrm{CNTF} / \mathrm{Ni}-\mathrm{Co}, \mathrm{CNTF} / \mathrm{Ni}-\mathrm{Co}-$ $\mathrm{Mn}$ and CNTF/Ni-Co-Mn-Mo NS, NTF/Ni-Co-Mn-Mo NS/CNTN electrode demonstrates the smallest $i R$ drop. This is mainly due to that the entanglement of CNTN on the quaternary metal oxide sheet is helpful for effectively reducing the overall resistance throughout the structure. Besides, the hierarchical-porous structure can provide extra channels for electrolyte penetration, which would ultimately enhance the redox reactions in the CNTF/NiCo-Mn-Mo NS/CNTN electrode. More detailed electrochemical performance of CNTF/Ni-Co-Mn-Mo NS/ CNTN electrode is provided by CV and GCD measurements. Fig. $4 \mathrm{c}$ shows the CV curves of the CNTF/Ni-CoMn-Mo NS/CNTN electrode at different scan rates. The $\mathrm{CV}$ curves display a pair of wide redox peaks with ascended peak current values along with the increase of scan rate, evidencing the rapid reversible electrochemical reactions and good reversibility of the active material.

To get a clear understanding of the surface redox reaction kinetics of the quaternary metal oxide-based electrode, the CNTF/Ni-Co-Mn-Mo NS electrode and CNTF/Ni-Co-Mn-Mo NS/CNTN electrode were analyzed through the Trasatti analysis to quantify the total stored charges $\left(q_{\mathrm{T}}\right)$, and the charges stored at the less easily accessible inner surface $\left(q_{\mathrm{i}}\right)$ and straightforwardly ionaccessible outer surface $\left(q_{\mathrm{o}}\right)$ during the energy storage process [34-36]. Since $q_{\mathrm{o}}$ is independent of scan rates and non-diffusion-controlled, high $q_{\mathrm{o}} / q_{\mathrm{T}}$ ratio indicates fast electrochemical kinetics [37]. It can be seen from Fig. 4d, e and Fig. S6 that the CNTF/Ni-Co-Mn-Mo NS/CNTN electrode demonstrates a much higher $q_{\mathrm{o}} / q_{\mathrm{T}}$ value of $52.15 \%$ than the CNTF/Ni-Co-Mn-Mo NS electrode (22.70\%), verifying enhanced charge storage process triggered by the CNTF/Ni-Co-Mn-Mo NS/CNTN electrode.

The CNTF/Ni-Co-Mn-Mo NS/CNTN electrode was further tested with GCD at various discharge current densities in the range of $1-10 \mathrm{~mA} \mathrm{~cm}^{-2}$. From Fig. 4f, consistent battery-type redox plateaus and symmetric charge-discharge time ranges are observed, confirming the good reversibility and coulombic efficiency of the electrode. Based on the GCD curves, the specific capacitances of the flexible CNTF/Ni-Co, CNTF/Ni-Co-Mn, CNTF/Ni-Co-Mn-Mo NS and CNTF/Ni-Co-Mn-Mo NS/ CNTN electrodes at different current densities were calculated and given in Fig. 4g and Fig. S7c. Among different types of mixed transition metal oxide-decorated CNTF samples, the highest specific capacitance of $13.81 \mathrm{~F} \mathrm{~cm}^{-2}$ $\left(2015.00 \mathrm{~F} \mathrm{~g}^{-1}\right)$ is reached by the CNTF/Ni-Co-Mn-Mo NS electrode at the discharge current of $1 \mathrm{~mA} \mathrm{~cm}^{-2}$, indicating that the complex valence states of quaternary metal oxide and its porous structure can effectively improve the energy storage performance of the electrode. While after CNTN deposition, the specific capacitance of $\mathrm{CNTF} / \mathrm{Ni}-\mathrm{Co}-\mathrm{Mn}-\mathrm{Mo} \mathrm{NS} / \mathrm{CNTN}$ is further improved to $15.39 \mathrm{~F} \mathrm{~cm}^{-2}\left(2243.42 \mathrm{~F} \mathrm{~g}^{-1}\right)$ at the current density of $1 \mathrm{~mA} \mathrm{~cm}{ }^{-2}$, which is much higher than recently reported studies about ternary metal oxide/hydroxide/sulfide active materials $[16,21,20]$ and the value also exceeds most of previously reported flexible electrodes based on transition metal oxides (Table S1). It should be noted that at the increased discharge current of $10 \mathrm{~mA} \mathrm{~cm}^{-2}$, a high specific capacitance of $8.01 \mathrm{~F} \mathrm{~cm}^{-2}\left(1179 \mathrm{~F} \mathrm{~g}^{-1}\right)$ can still be maintained for CNTF/Ni-Co-Mn-Mo NS/CNTN. Furthermore, long-term cycling performances of the CNTF/ Ni-Co-Mn-Mo NS/CNTN, CNTF/Ni-Co-Mn-Mo NS, $\mathrm{CNTF} / \mathrm{Ni}-\mathrm{Co}-\mathrm{Mn}$ and $\mathrm{CNTF} / \mathrm{Ni}-\mathrm{Co}$ were evaluated by repeating GCD measurements, as shown in Fig. $4 \mathrm{~h}$. After 3000 cycles, the CNTF/Ni-Co-Mn-Mo NS/CNTN maintains an excellent capacity retention of $106.75 \%$ (with a good Faradic efficiency of $97.30 \%$; Fig. $4 \mathrm{~h}$ inset; the increased capacitance retention is due to the electrochemical activation of the electrode during repeated charging-discharging processes), which is better than the CNTF/Ni-Co-Mn-Mo NS (90.04\%), CNTF/Ni-Co-Mn $(91.87 \%)$ and CNTF/Ni-Co (87.70 \%), indicating its excellent electrochemical stability.

The outstanding specific capacity, increased redox reaction kinetics and cycling performance of the $\mathrm{CNTF} / \mathrm{Ni}$ Co-Mn-Mo NS/CNTN electrode are mainly attributed to 
its synergic features derived from the highly electrochemical active quaternary metal oxide and conductive CNTs, as schematically annotated in Fig. 4i. First, CNTF as the flexible substrate and current collector supports the integrity of the whole freestanding electrode and provides efficient transportation of electrons into and out of the electrode. Second, the Ni-Co-Mn-Mo oxide active materials are expected to offer an evident enhancement of electrochemical activities and accelerated electron transportation, due to the rich valence change provided by $\mathrm{Ni}$, $\mathrm{Co}, \mathrm{Mn}, \mathrm{Mo}$ and the improved conductivity provided by Mo [16,18]. Third, the open macropores formed by the nanosheets favor the fast penetration of electrolyte ions into the whole active matrix, and at the same time the mesopores located on the thin oxide nanosheets provide extra paths for electrolyte transportation. In other words, these hierarchical porous channels ensure efficient mass transfer and improve the contact between the active surface and the electrolyte, leading to the maximized utilization of the active materials. Forth, the CNTN entanglement can improve the conductivity of the active material and act as the electron "superhighways" to promote the electron transfer rate. Fifth, the verticallyaligned multi-level porous structure can provide adequate spaces for structure variation and CNTN entanglement can restrict the distortion and disintegration of the active material during repetitive electrochemical cycling, enabling long term cycling stability. As a result, excellent energy storage performance is achieved by the CNTF/NiCo-Mn-Mo NS/CNTN electrode.

To further study the applicability of the CNTF/Ni-CoMn-Mo NS/CNTN electrode in flexible energy storage devices, an asymmetric supercapacitor was fabricated with the CNTF/Ni-Co-Mn-Mo NS/CNTN electrode as the positive electrode and carbon cloth as the negative electrode (Fig. 5a). Carbon cloth has been demonstrated to possess favorable flexibility and conductivity, which meets the requirement for wearable supercapacitor electrodes. The carbon cloth used in this work was specially made through combined textile technology and $\mathrm{KOH}$ activation to introduce $\mathrm{N} / \mathrm{O}$ containing functional groups. Due to the enriched surface functional groups, an excellent specific capacitance of $5138.4 \mathrm{mF} \mathrm{cm}^{-2}$ was obtained by the carbon cloth electrode in $1 \mathrm{~mol} \mathrm{~L}^{-1} \mathrm{KOH}$ solution (Fig. S8). Consequently, it can work as a highperformance negative electrode for the asymmetric supercapacitor. Fig. $5 \mathrm{~b}$ presents the corresponding $\mathrm{CV}$ curves of the CNTF/Ni-Co-Mn-Mo NS/CNTN electrode and carbon cloth electrode tested in a three-electrode system at the scan rate of $10 \mathrm{mV} \mathrm{s}^{-1}$. The CNTF/Ni-Co-
Mn-Mo NS/CNTN displays a stable CV without water decomposition in $0-0.5 \mathrm{~V}$, while carbon cloth electrode shows a stable $\mathrm{CV}$ potential range of $-1-0 \mathrm{~V}$, indicating that the asymmetric supercapacitor can reach a maximum operational voltage window of $1.5 \mathrm{~V}$. Fig. $5 \mathrm{c}-\mathrm{i}$ give the typical measured energy storage performances of the flexible asymmetric supercapacitor. In fact, a stable $1.5 \mathrm{~V}$ voltage window of the device can be obtained with no signs of water decomposition in CVs (Fig. 5c) and overcharging region in GCDs (Fig. 5d), verifying an excellent electrochemical stability at high voltages. The specific areal capacitances $\left(C_{\mathrm{a}}\right)$ at different voltages were calculated based on Fig. 5d. On account of the extended operating voltage, an increase of 1.26-fold is observed for $C_{\mathrm{a}}$ from $2720 \mathrm{mF} \mathrm{cm}^{-2}$ at $0.8 \mathrm{~V}$ to $3418 \mathrm{mF} \mathrm{cm}^{-2}$ at $1.5 \mathrm{~V}$ (Fig. 5e). Significantly, the energy density increases linearly from 0.24 to $1.06 \mathrm{~mW} \mathrm{~h} \mathrm{~cm}^{-2}$, demonstrating an increment of $441 \%$ (Fig. 5f). A 2.03 times increase can also be observed in the power density $P_{\mathrm{a}}$, which rises from $3.15 \mathrm{~mW} \mathrm{~cm}^{-2}$ to $6.39 \mathrm{~mW} \mathrm{~cm}^{-2}$ (Fig. 5f).

For detailed investigations of various electrochemical parameters of the asymmetric flexible device, CVs were recorded at various scan rate from 2 to $50 \mathrm{mV} \mathrm{s}^{-1}$ with a voltage window of $1.5 \mathrm{~V}$ (Fig. $5 \mathrm{~g}$ ). Wide redox peaks appear in the CV curves obtained among the whole scan rate range, implying rapid reversible faradic redox reactions and high electrochemical capability of the electrode. With the increase of the scan rates, the CV currents are distinctively enlarged, verifying eficient $I-V$ response of the flexible supercapacitor. Besides, GCD measurements were conducted to get further information about the supercapacitor, as shown in Fig. 5h. At various current densities, nonlinear GCD curves reveal the ideal pseudocapacitive property. Fig. $5 \mathrm{i}$ demonstrates the calculated specific areal capacitances of the supercapacitor according to GCD curves. It should be noted that a superior specific capacitance of $3738 \mathrm{mF} \mathrm{cm}^{-2}$ is achieved at the current density of $4 \mathrm{~mA} \mathrm{~cm}^{-2}$ and retains more than $70 \%$ as the current density increased to $20 \mathrm{~mA} \mathrm{~cm}^{-2}$, indicating its outstanding rate performance. The EIS results show that the ESR of the asymmetric supercapacitor based on the CNTF/Ni-Co-Mn-Mo NS/CNTN electrode $(8.22 \Omega)$ is lower than the device based on the CNTF/Ni-Co-Mn-Mo NS electrode (13.22 $\Omega$ ), due to the deposition of CNTN (Fig. S9).

Based on the high energy storage ability of the reasonably designed electrode and the extended potential window, the flexible supercapacitor illustrates an extraordinary specific areal energy density of $1.17 \mathrm{~mW} \mathrm{~h} \mathrm{~cm}{ }^{-2}$ and a specific areal power density of $13.40 \mathrm{~mW} \mathrm{~cm}^{-2}$. 

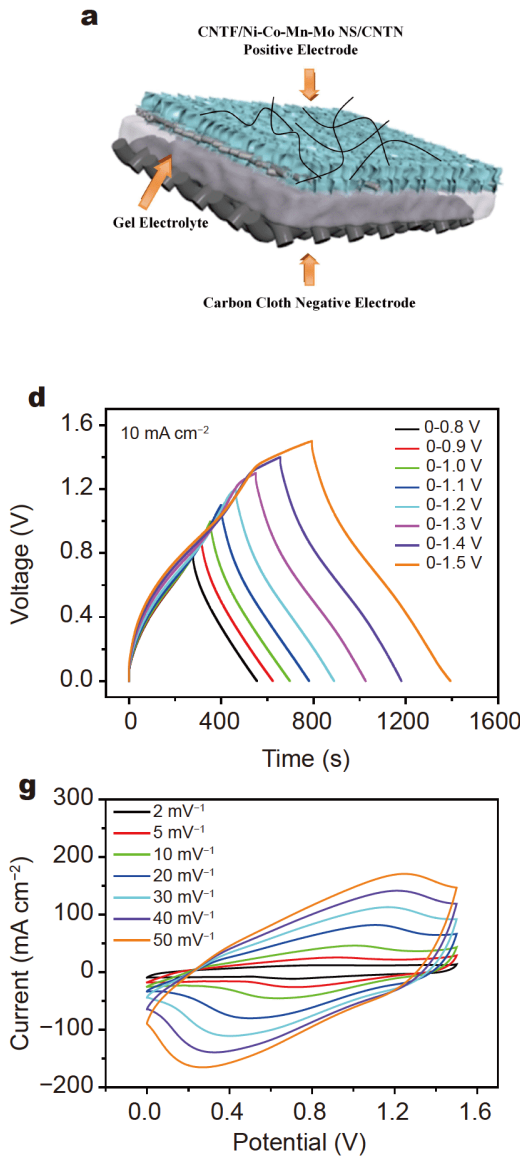
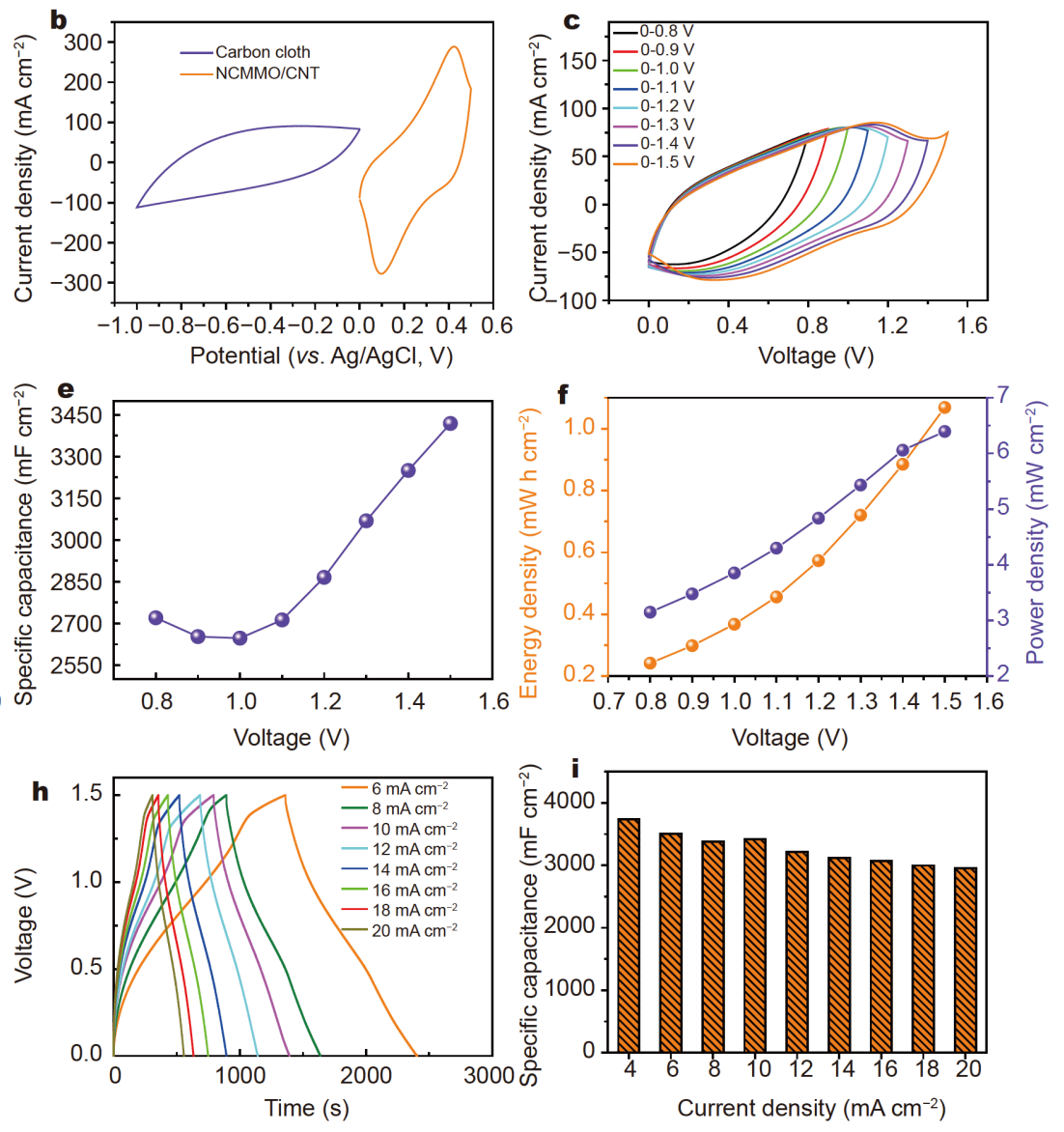

Figure 5 (a) Schematic illustration of the asymmetric supercapacitor. (b) CV curves of carbon cloth and CNTF/Ni-Co-Mn-Mo NS/CNTN. (c) CV curves of the supercapacitor tested at different potentials at the scan rate of $20 \mathrm{mV} \mathrm{s}^{-1}$. (d) GCD curves of the asymmetric supercapacitor tested at different potentials. (e) Specific areal capacitance at different voltages. (f) Energy density, and power density as functions of voltage. (g) CV curves of the supercapacitor at different scan rates. (h) GCD curves of the supercapacitor at different current densities. (i) Specific areal capacitance as a function of current density.

Fig. 6a is the Ragone plot showing the specific areal energy density with respect to the specific areal power density of the asymmetric device compared with other recently reported flexible supercapacitor systems [38-46]. As can be observed, the specific areal energy density and power density reported in this work exceed most of the existing flexible devices, such as supercapacitors based on the sandwich-type $\mathrm{GaN} / \mathrm{MnO}_{2} / \mathrm{MnON}$ composite $\left(0.061 \mathrm{~mW} \mathrm{~h} \mathrm{~cm}^{-2}, 10 \mathrm{~mW} \mathrm{~cm}^{-2}\right)$ [38], silver-quantumdot-modified $\mathrm{MoO}_{3}$ and $\mathrm{MnO}_{2}$ paper-like electrode $\left(0.046 \mathrm{~mW} \mathrm{~h} \mathrm{~cm}^{-2}, 0.02 \mathrm{~mW} \mathrm{~cm}^{-2}\right)$ [39], and CNT@3D graphene aerogel electrode $\left(0.427 \mathrm{~mW} \mathrm{~h} \mathrm{~cm}^{-2}\right.$, $3.55 \mathrm{~mW} \mathrm{~cm}^{-2}$ ) [40]. The high energy density renders miniaturization and portable applications possible. It should be noted that three small pieces $\left(0.5 \times 0.5 \mathrm{~cm}^{2}\right.$ active area each) of our flexible supercapacitors connected in series are able to power an LED display panel with three characters "SZU" (composed of 104 red LED lights, Fig. 6b), illustrating its ability for practical applications.

To demonstrate the flexibility and performance stability of the supercapacitor under mechanical deformations, the flexible supercapacitor was clamped on a specially made fixture which can automatically bend the device to different bending angles (Fig. 6c) and the electrochemical performance was monitored in real time. Fig. $6 \mathrm{~d}$ exhibits the CV response of the flexible device at various bending status. CV curves at different bending angles do not show substantial changes and keep the redox peaks well, confirming excellent electrochemical stability and nearly identical capacitive performance of the device under deformations. Excellent mechanical robustness can also be observed for the asymmetric flexible device, which demonstrates a $96.2 \%$ capacitance retention after 100 bending cycles under $90^{\circ}$ (Fig. S10). 


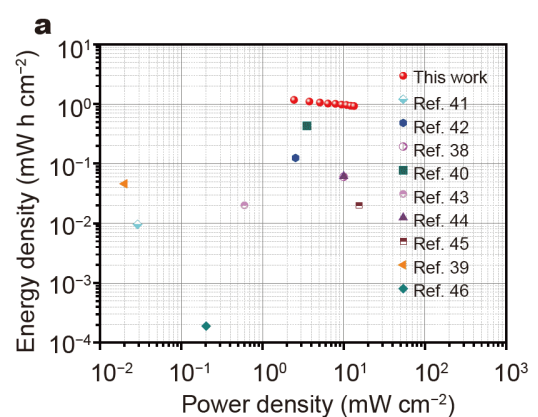

b

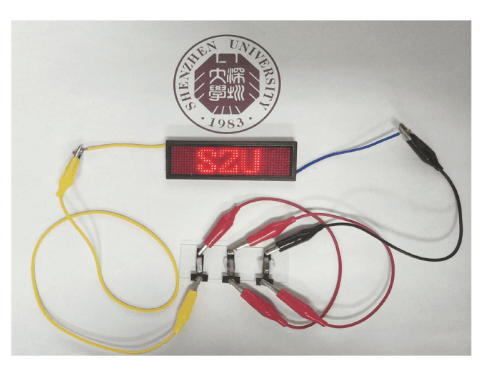

c

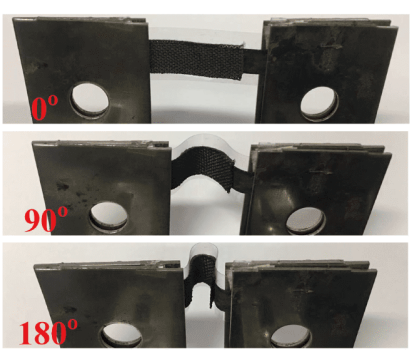

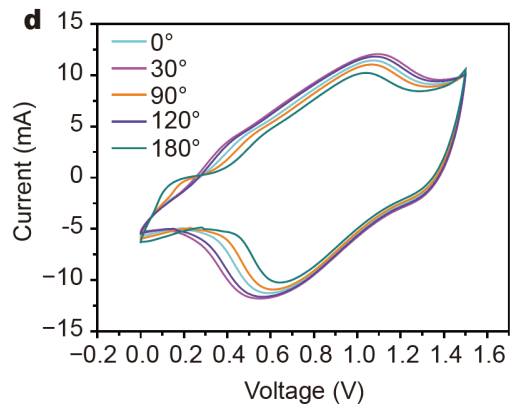

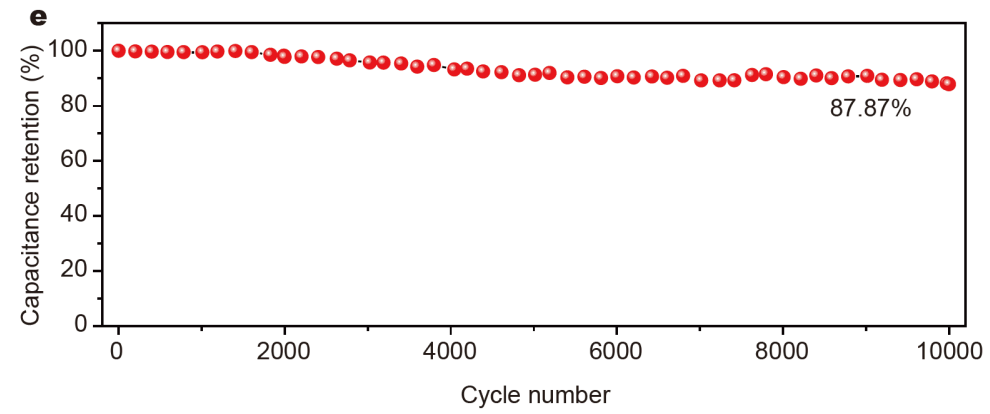

Figure 6 (a) Ragone plot of the present work compared with previously reported supercapacitors. (b) Optical image of an LED display panel lightened by three supercapacitors connected in series. (c) Optical images of the flexible supercapacitor at different bending angles. (d) CV curves of the flexible supercapacitor at different bending angles. (e) Capacitance retention during 10,000 GCD cycles.

Another important evaluation criterion of the energy storage devices is their service-life. In order to study the stability of the CNTF/Ni-Co-Mn-Mo NS/CNTN based supercapacitor, the device was examined by GCD measurements for 10,000 cycles at a sufficiently high current density of $40 \mathrm{~mA} \mathrm{~cm}^{-2}$ (Fig. 6e). Notably, the specific capacitance exhibits a slow decrease rate with the increase of the cycle number and excellent capacitance retention of $87.87 \%$ is obtained after 10,000 charge-discharge cycles.

\section{CONCLUSION}

In summary, we fabricated a quaternary metal oxide and CNT-based hierarchical-porous flexible electrode (CNTF/ Ni-Co-Mn-Mo NS/CNTN). Due to the synergistic effect of the highly electrochemical active quaternary metal oxide nanosheets, highly conductive CNTs, and the hierarchical porous structure, the flexible electrode demonstrates outstanding energy storage performance with a specific areal capacitance of $15.39 \mathrm{~F} \mathrm{~cm}^{-2}\left(2243.42 \mathrm{~F} \mathrm{~g}^{-1}\right)$ along with excellent cycling performances, which outperforms most of the state-of-the-art flexible electrodes reported previously. Based on the CNTF/Ni-Co-Mn-Mo NS/CNTN flexible electrode, an asymmetric flexible supercapacitor was fabricated. The supercapacitor demonstrates outstanding electrochemical properties with the stable output voltage of $1.5 \mathrm{~V}$ and a specific capacitance of $3738 \mathrm{mF} \mathrm{cm}^{-2}$, corresponding to a high energy density of $1.17 \mathrm{~mW} \mathrm{~h} \mathrm{~cm}^{-2}$. Additionally, excellent flexibility and performance stability can be observed for the supercapacitor, which delivers stable performance output even under $180^{\circ}$ bend and high capacitance retention of $87.87 \%$ after 10,000 GCD cycles at the high current density.

Received 17 January 2020; accepted 8 April 2020; published online 9 June 2020

1 Shi L, Li D, Yu J, et al. Uniform core-shell nanobiscuits of $\mathrm{Fe}_{7} \mathrm{~S}_{8} @ \mathrm{C}$ for lithium-ion and sodium-ion batteries with excellent performance. J Mater Chem A, 2018, 6: 7967-7976

2 Roy A, Ray A, Saha S, et al. NiO-CNT composite for high performance supercapacitor electrode and oxygen evolution reaction. Electrochim Acta, 2018, 283: 327-337

3 Hadjipaschalis I, Poullikkas A, Efthimiou V. Overview of current and future energy storage technologies for electric power applications. Renew Sustain Energy Rev, 2019, 13: 1513-1522

4 Strauss V, Marsh K, Kowal MD, et al. A simple route to porous graphene from carbon nanodots for supercapacitor applications. Adv Mater, 2018, 30: 1704449

5 Woodward RT, Markoulidis F, De Luca F, et al. Carbon foams from emulsion-templated reduced graphene oxide polymer composites: electrodes for supercapacitor devices. J Mater Chem A, 2018, 6: 1840-1849

6 Zhou J, Yu J, Shi L, et al. A conductive and highly deformable all- 
pseudocapacitive composite paper as supercapacitor electrode with improved areal and volumetric capacitance. Small, 2018, 14: 1803786

7 Guo Y, Hong X, Wang Y, et al. Multicomponent hierarchical Cudoped NiCo-LDH/CuO double arrays for ultralong-life hybrid fiber supercapacitor. Adv Funct Mater, 2019, 29: 1809004

$8 \mathrm{Yu}$ J, Lu W, Pei S, et al. Omnidirectionally stretchable high-performance supercapacitor based on isotropic buckled carbon nanotube films. ACS Nano, 2016, 10: 5204-5211

9 Wang G, Oswald S, Löffler M, et al. Beyond activated carbon: graphite-cathode-derived Li-ion pseudocapacitors with high energy and high power densities. Adv Mater, 2019, 31: 1807712

10 Li X, Li X, Cheng J, et al. Fiber-shaped solid-state supercapacitors based on molybdenum disulfide nanosheets for a self-powered photodetecting system. Nano Energy, 2016, 21: 228-237

$11 \mathrm{Yu} \mathrm{J,} \mathrm{Lu} \mathrm{W,} \mathrm{Smith} \mathrm{JP,} \mathrm{et} \mathrm{al.} \mathrm{A} \mathrm{high} \mathrm{performance} \mathrm{stretchable}$ asymmetric fiber-shaped supercapacitor with a core-sheath helical structure. Adv Energy Mater, 2017, 7: 1600976

12 Zhang Q, Wang X, Pan Z, et al. Wrapping aligned carbon nanotube composite sheets around vanadium nitride nanowire arrays for asymmetric coaxial fiber-shaped supercapacitors with ultrahigh energy density. Nano Lett, 2017, 17: 2719-2726

13 Wang $\mathrm{T}$, Guo $\mathrm{Y}$, Zhao B, et al. $\mathrm{NiCo}_{2} \mathrm{O}_{4}$ nanosheets in-situ grown on three dimensional porous $\mathrm{Ni}$ film current collectors as integrated electrodes for high-performance supercapacitors. J Power Sources, 2015, 286: 371-379

14 Li M, Yang W, Huang Y, et al. Hierarchical mesoporous $\mathrm{Co}_{3} \mathrm{O}_{4} @$ $\mathrm{ZnCo}_{2} \mathrm{O}_{4}$ hybrid nanowire arrays supported on $\mathrm{Ni}$ foam for highperformance asymmetric supercapacitors. Sci China Mater, 2018, 61: 1167-1176

15 Li L, Zhang Y, Shi F, et al. Spinel manganese-nickel-cobalt ternary oxide nanowire array for high-performance electrochemical capacitor applications. ACS Appl Mater Interfaces, 2014, 6: 1804018047

16 Sun J, Zhang Q, Wang X, et al. Constructing hierarchical dandelion-like molybdenum-nickel-cobalt ternary oxide nanowire arrays on carbon nanotube fiber for high-performance wearable fiber-shaped asymmetric supercapacitors. J Mater Chem A, 2017, 5: 21153-21160

17 Maitra A, Das AK, Bera R, et al. An approach to fabricate PDMS encapsulated all-solid-state advanced asymmetric supercapacitor device with vertically aligned hierarchical $\mathrm{Zn}$-Fe-Co ternary oxide nanowire and nitrogen doped graphene nanosheet for high power device applications. ACS Appl Mater Interfaces, 2017, 9: 59475958

18 Wu C, Cai J, Zhang Q, et al. Hierarchical mesoporous zinc-nickelcobalt ternary oxide nanowire arrays on nickel foam as high-performance electrodes for supercapacitors. ACS Appl Mater Interfaces, 2015, 7: 26512-26521

19 Sahoo S, Nguyen TT, Shim JJ. Mesoporous Fe-Ni-Co ternary oxide nanoflake arrays on $\mathrm{Ni}$ foam for high-performance supercapacitor applications. J Industrial Eng Chem, 2018, 63: 181-190

20 Huang ZH, Sun FF, Batmunkh M, et al. Zinc-nickel-cobalt ternary hydroxide nanoarrays for high-performance supercapacitors. J Mater Chem A, 2019, 7: 11826-11835

21 Wang X, Zhang Q, Sun J, et al. Facile synthesis of hierarchical porous manganese nickel cobalt sulfide nanotube arrays with enhanced electrochemical performance for ultrahigh energy density fiber-shaped asymmetric supercapacitors. J Mater Chem A, 2018, 6: $8030-8038$
22 Yuan $\mathrm{C}, \mathrm{Wu} \mathrm{HB}$, Xie $\mathrm{Y}$, et al. Mixed transition-metal oxides: design, synthesis, and energy-related applications. Angew Chem Int Ed, 2014, 53: 1488-1504

23 Yu J, Zhou J, Yao P, et al. Antimonene engineered highly deformable freestanding electrode with extraordinarily improved energy storage performance. Adv Energy Mater, 2019, 9: 1902462

24 Yuan C, Yang L, Hou L, et al. Growth of ultrathin mesoporous $\mathrm{Co}_{3} \mathrm{O}_{4}$ nanosheet arrays on $\mathrm{Ni}$ foam for high-performance electrochemical capacitors. Energy Environ Sci, 2012, 5: 7883-7887

25 Nagaraju G, Sekhar SC, Yu JS. Utilizing waste cable wires for highperformance fiber-based hybrid supercapacitors: an effective approach to electronic-waste management. Adv Energy Mater, 2017, 8: 1702201

$26 \mathrm{Hu}$ CC, Chang KH, Lin MC, et al. Design and tailoring of the nanotubular arrayed architecture of hydrous $\mathrm{RuO}_{2}$ for next generation supercapacitors. Nano Lett, 2006, 6: 2690-2695

$27 \mathrm{Lu}$ XF, Wang AL, Xu H, et al. High-performance supercapacitors based on $\mathrm{MnO}_{2}$ tube-in-tube arrays. J Mater Chem A, 2015, 3: 16560-16566

$28 \mathrm{Lu} \mathrm{W}, \mathrm{Zu} \mathrm{M}$, Byun JH, et al. State of the art of carbon nanotube fibers: opportunities and challenges. Adv Mater, 2012, 24: 18051833

29 Jothi PR, Kannan S, Velayutham G. Enhanced methanol electrooxidation over in-situ carbon and graphene supported one dimensional $\mathrm{NiMoO}_{4}$ nanorods. J Power Sources, 2015, 277: 350-359

30 Houssenbay S, Kasztelan S, Toulhoat $\mathrm{H}$, et al. Nature of the different nickel species in sulfided bulk and alumina-supported nickel-molybdenum hydrotreating catalysts. J Phys Chem, 1989, 93: 7176-7180

31 Zhang GQ, Wu HB, Hoster $\mathrm{HE}$, et al. Single-crystalline $\mathrm{NiCo}_{2} \mathrm{O}_{4}$ nanoneedle arrays grown on conductive substrates as binder-free electrodes for high-performance supercapacitors. Energy Environ Sci, 2012, 5: 9453-9456

32 Chen H, Yan Z, Liu XY, et al. Rational design of microsphere and microcube $\mathrm{MnCO}_{3} @ \mathrm{MnO}_{2}$ heterostructures for supercapacitor electrodes. J Power Sources, 2017, 353: 202-209

33 Cao Y, Li W, Xu K, et al. $\mathrm{MnMoO}_{4} \cdot 4 \mathrm{H}_{2} \mathrm{O}$ nanoplates grown on a $\mathrm{Ni}$ foam substrate for excellent electrochemical properties. J Mater Chem A, 2014, 2: 20723-20728

34 Augustyn V, Come J, Lowe MA, et al. High-rate electrochemical energy storage through $\mathrm{Li}^{+}$intercalation pseudocapacitance. Nat Mater, 2013, 12: 518-522

35 Ardizzone S, Fregonara G, Trasatti S. "Inner" and "outer" active surface of $\mathrm{RuO}_{2}$ electrodes. Electrochim Acta, 1990, 35: 263-267

36 Yan J, Ren CE, Maleski K, et al. Flexible MXene/graphene films for ultrafast supercapacitors with outstanding volumetric capacitance. Adv Funct Mater, 2017, 27: 1701264

37 Augustyn V, Simon P, Dunn B. Pseudocapacitive oxide materials for high-rate electrochemical energy storage. Energy Environ Sci, 2014, 7: 1597-1614

38 Wang S, Shao Y, Liu W, et al. Elastic sandwich-type $\mathrm{GaN} / \mathrm{MnO}_{2} /$ $\mathrm{MnON}$ composites for flexible supercapacitors with high energy density. J Mater Chem A, 2018, 6: 13215-13224

39 Zhang $\mathrm{X}, \mathrm{Fu} \mathrm{Q}$, Huang $\mathrm{H}$, et al. Silver-quantum-dot-modified $\mathrm{MoO}_{3}$ and $\mathrm{MnO}_{2}$ paper-like freestanding films for flexible solidstate asymmetric supercapacitors. Small, 2019, 15: 1805235

40 Liu Q, Wan J, Li Y, et al. Elucidating Li-ion adsorption and diffusion behavior on the surface of $\mathrm{Cu}_{0.7} \mathrm{Co}_{2.3} \mathrm{O}_{4}$ and improvement of performance as flexible full solid-state supercapacitor. Electrochim Acta, 2019, 293: 380-389 
41 Liu X, Wang J, Yang G. Amorphous nickel oxide and crystalline manganese oxide nanocomposite electrode for transparent and flexible supercapacitor. Chem Eng J, 2018, 347: 101-110

42 Liu X, Guan C, Hu Y, et al. 2D metal-organic frameworks derived nanocarbon arrays for substrate enhancement in flexible supercapacitors. Small, 2018, 14: 1702641

43 Sun K, Feng E, Zhao G, et al. A single robust hydrogel film based integrated flexible supercapacitor. ACS Sustain Chem Eng, 2019, 7: 165-173

44 Yang C, Zhang L, Hu N, et al. Reduced graphene oxide/polypyrrole nanotube papers for flexible all-solid-state supercapacitors with excellent rate capability and high energy density. J Power Sources, 2016, 302: 39-45

45 Gao K, Shao Z, Li J, et al. Cellulose nanofiber-graphene all solidstate flexible supercapacitors. J Mater Chem A, 2013, 1: 63-67

46 Avasthi P, Kumar A, Balakrishnan V. Aligned CNT forests on stainless steel mesh for flexible supercapacitor electrode with high capacitance and power density. ACS Appl Nano Mater, 2019, 2: 1484-1495

Acknowledgements This work was supported by the National Natural Science Foundation of China (51673117 and 21805193), the Science and Technology Innovation Commission of Shenzhen (JSGG20160226201833790, JCYJ20170818093832350, JCYJ20170818112409808 and JSGG20170824112840518), and China Postdoctoral Science Foundation (2017M622786, 2017M622787 and 2019M653067).

Author contributions Yao P performed the experiments. Zhou J, Zhang $\mathrm{S}$ and Zhang $\mathrm{M}$ analyzed the data. Yu J wrote the manuscript. Liu $\mathrm{H}$, Yang B, Zhang T, Zhu C and Xu J gave some valuable comments.

Conflict of interest The authors declare no conflict of interest.

Supplementary information Supporting data are available in the online version of the paper.

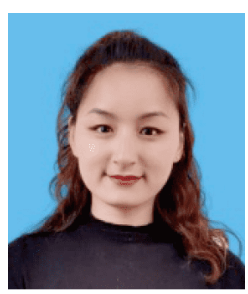

Pingping Yao is currently a post graduate student in the College of Chemistry and Environmental Engineering, Shenzhen University. Her research interests include material design and synthesis of nanomaterials for energy storage.

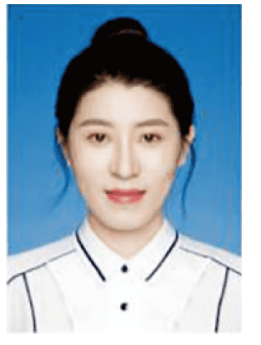

Jiali Yu received her $\mathrm{PhD}$ degree in chemical engineering and technology from Harbin Institute of Technology in 2017. She is currently an associate research fellow in the College of Chemistry and Environmental Engineering, Shenzhen University. Dr. Yu's research interest centers on developing fundamental insights and materials design principles for energy storage.

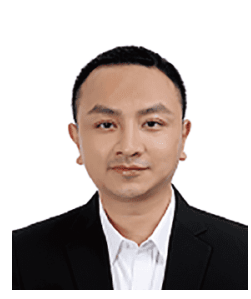

Caizhen Zhu is currently an associate professor in the Institute of Low-dimensional Materials Genome Initiative, College of chemistry and Environmental Engineering, Shenzhen University. He received his $\mathrm{PhD}$ degree in polymer physics and chemistry from the Institute of Chemistry, Chinese Academy of Sciences in 2012. His research interests include small-angle $\mathrm{X}$-ray scattering and the synthesis and application of nanomaterials for energy storage.

\section{“三明治”多孔四元金属氧化物纳米片/碳纳米管柔 性薄膜电极的构建及其性能研究}

姚平平 ${ }^{1}$, 于佳立 ${ }^{1 *}$, 周㷊 ${ }^{1}$, 张硕 ${ }^{1}$, 张盟 ${ }^{1}$, 刘会超 ${ }^{1}$, 杨波 ${ }^{1}$, 张涛 ${ }^{2,3}$, 朱才镇 ${ }^{*}$, 徐坚 ${ }^{1}$

摘要 混合金属氧化物具有优异的电化学活性, 在高性能超级电容 电极领域具有广阔的应用前景. 然而, 电极内离子动力学和电子动 力学的迟滞从根本上限制了其电化学性能的进一步提高. 为了弥 补这一不足, 本文通过原位化学反应在自支撑碳纳米管薄膜 (CNTF) 表面生长四元过渡金属氧化物纳米片(Ni-Co-Mn-Mo NS), 并进一步在纳米片上沉积碳纳米管导电网络(CNTN), 得到了具有 “三明治”结构的多孔柔性电极薄膜(CNTF/Ni-Co-Mn-Mo NS/ $\mathrm{CNTN})$. 得益于高电化学活性四元金属氧化物纳米片和碳纳米管 (CNT) 的协同作用以及合理的分层设计, 该柔性电极拥有出色的储 能性能, 在 $1 \mathrm{~mol} \mathrm{~L}^{-1} \mathrm{KOH}$ 中能达到 $15.39 \mathrm{~F} \mathrm{~cm}^{-2}\left(2243.42 \mathrm{~F} \mathrm{~g}^{-1}\right)$ 的高 比面积电容, 优于大多数已报道的柔性电极. 基于 $\mathrm{CNTF} / \mathrm{Ni}-\mathrm{Co}-$ Mn-Mo NS/CNTN电极的非对称柔性超级电容器拥有优异的电化 学性能, 其稳定的输出电压为 $1.5 \mathrm{~V}$, 比电容可达 $3738.12 \mathrm{mF} \mathrm{cm}^{-2}$, 对应于 $1.17 \mathrm{~mW} \mathrm{~h} \mathrm{~cm}{ }^{-2}$ 的高能量密度. 此外, 超级电容器具有出色 的柔韧性和稳定性, 即使在 $180^{\circ}$ 弯曲下也能稳定工作, 并且在高电 流密度下经过 10000 次充放电循环后其比电容仍能保持 $87.87 \%$. 这 种独特的设计为高性能柔性储能器件的发展开辟了新的方向. 